ISSN: 1812-1217

E- ISSN: 1998-0345

Zana Qadr Omer

BDS, MSc., PhD (Asst. Prof.)

\author{
Seerwan Ahmed \\ BDS, MSc \\ Muhamad Hussein \\ BDS., MSc (lec.)
}

\section{Developing white spot lesion (WSL) in patients with Fixed orthodontic appliance in Erbil city of Iraq}

Dep.of pedodontic,orthodontics and preventive dentistry

College of Dentistry, Hawlere medical University

Ministry of health

Dep. of pedodontic, orthodontics and preventive dentistry College of Dentistry,Hawlere medical University

\begin{abstract}
الخلاصة

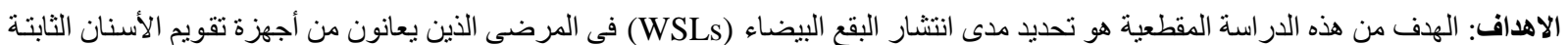

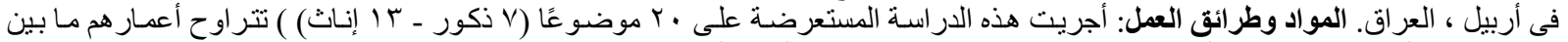

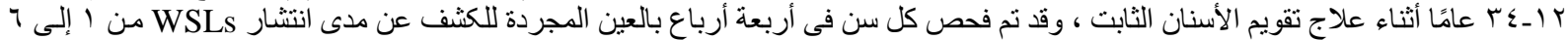

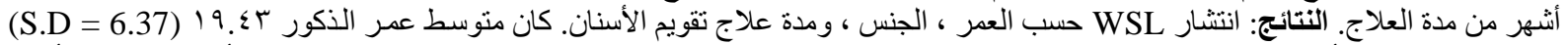

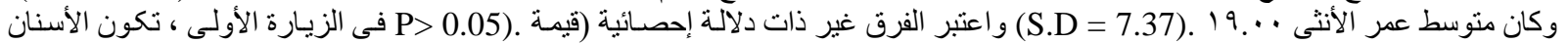

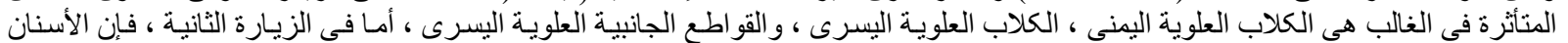

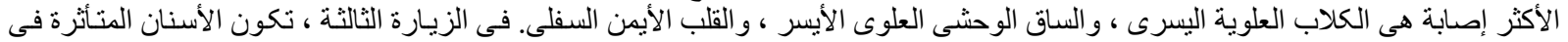

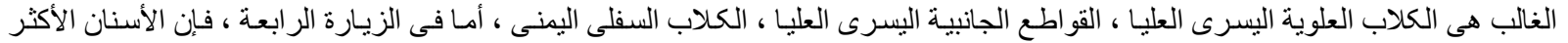

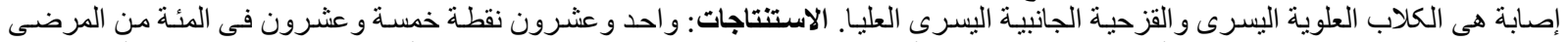

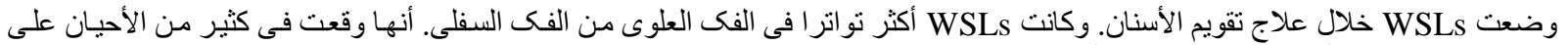

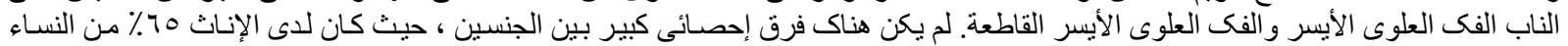

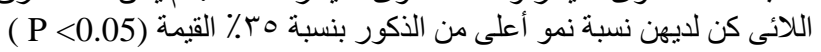

\begin{abstract}
AIMS: of this cross sectional study is to specify the occurrence of white spot lesion (WSLs) in patients with orthodontic attachment in Erbil, Iraq. MATERIALS AND METHODS: This cross-sectional study was carried out on 20 subjects ( 7 male - 13 female) their age ranged between 12-34 years old. During fixed orthodontic treatment each tooth in four quadrants was examined by naked eye to detect the occurrence of WSLs from the 1 month to 6 month of treatment duration. RESULTS: The prevalence of WSL according to age, gender, and duration of the orthodontic treatment. The mean age of male were $19.43(\mathrm{~S} . \mathrm{D}=6.37)$ and the mean age of female were $19.00(\mathrm{~S} . \mathrm{D}=7.37)$; but statistically calculated non- significant $(\mathrm{P}$-value $>0.05)$. In the first visit the mostly affected teeth are upper right canine, upper left canine, and upper left lateral incisor, In second visit the most affected teeth are upper left canine, upper left lateral incisor, and lower right canine. In the third visit the mostly affected teeth are upper left canine, upper left lateral incisor, and lower right canine, In the fourth visit the most affected teeth are upper left canine and upper left lateral incisor. The frequency of WSLs increased with each visit of orthodontic treatment, the maximum occurrence of WSLs was found in the sixth visit $(21.25 \%)$ followed by fifth visit $(21 \%)$, fourth visit $(19.25 \%)$, third visit $(16.25 \%)$, second visit $(13.75 \%)$, and finally first visit (7.25\%). The mean of all visit equal to $16.45 \%$.CONCLUSION: $21.25 \%$ of patients in developing WSLs during orthodontic treatments were more attend in the upper than lower arch; they occurred most often on the upper left canine and upper left lateral incisor. There was statistically no significant male and female difference, females had a $65 \%$ of developing WSLs than males 35\% (P-value <0.05).Key words: Coenzyme Q10; Wound healing; Wound contraction ratio.
\end{abstract}

Key words: white spot, lesion, fixed appliance

Omer ZQ., Ahmed S., Saleh. MH. Developing white spot lesion (WSL) in patients with Fixed orthodontic appliance in Erbil city of Iraq. Al-Rafidain Dent J. 2019;19(1):52-59.

Received: 13/12/2019 Sent to Referees: 14/12/2019 Accepted for Publication: 31/12/2019

Al-Rafidain Dent J

Vol. 19, No1, 2019 


\section{INTRODUCTION}

The white spot lesion define as the first point of a caries bound on surface of teeth that can be seen with unaided eye that appears itself as a milky white opacity when located on smooth surface (Summitt et al, 2006). White discoloration of enamel can be arranged as dental fluorosis, opacity, or WSL. A set of criteria have been developed to recognize between fluorosis and opacity. Fluorosis is white/ yellowish lesion that is not well defined ,blends with normal enamel, and has uniform distribution in the mouth. Non fluoride opacity have a well determined, are more differentiated form around enamel, often located in the middle of the tooth, and randomly distributed (Moghaddam et al,2013.Creation of white spots during orthodontic treatment can occur as early as 4 weeks into processing and their prevalence among orthodontic patients ranges from $2 \%$ to $96 \%$. The labial surface of lateral incisors in gingival is the most common site for WSL and the upper posterior segments are the least common site, with males affected more in comparison with females (Joshua et $a l, 2010)$.

The aim of the present study is to determine the prevalence of white spot lesion (WSLs) in patients with fixed orthodontic appliances in Erbil, Iraq.

\section{MATERIALS AND METHODS}

For this study we taken consent from the Ethics commission in Hawler Medical University, college of Dentistry . The subjects comprised of all types of malocclusion with first month to sixth month of treatment duration in at least 20 patients, their age ranged between 12 to 34 years old attending to dental clinic. They were permanent residence in Erbil city.

All patients concerted to contribute in this survey ; General question were asked to the patients about; name, age, gender, address and telephone number. (Appendix-1).Materials used are teeth ,brackets ,distilled water and cotton role ; instruments used dental unit, dental probe (disposable) ,dental mirror (disposable) ,tweezers (disposable) and camera (shofu eye special class II).

Subjects were comfortably seated and asked to irrigate with distilled water to remove food debris and contaminated material (sticky foods) using air spray in order the teeth to be dried. Then each tooth in four quadrants, from central incisors to second premolar, was examined by naked eye to detect the prevalence of WSLs from the 1 month to 6 month of treatment duration. The patients' examination was performed in the dental clinic to detect the presence of WSLs. The teeth looked-on for examination from $2^{\text {nd }}$ premolar to $2^{\text {nd }}$ premolar in upper 
and lower arch .Teeth were air dried with triple syringe to remove saliva . Molars were excluded from the study as many molar teeth were banded obviating the visibility for WSL. just tooth surfaces gingival to the arch wire were examined for the presence of WSLs, as this is the area most prone to demineralization during orthodontic treatment. The teeth were optically examined on buccual surface after removing plaque with the help of instrument or distilled water and air water spray drying. Statistical analysis began by entering the data on computer using Microsoft Excel program. Data analysis calculated with SPSS version 21.The results were represented and arranged in tables, figures showing statistical analysis: t-test, rates and percentages.

Appendix (1): case sheet for patient $\left(1^{\text {st }}\right.$ visit before placement of fixed appliance and counted these WSL excluded from the data collection) (followed for 6 months).

\begin{tabular}{|c|c|c|c|c|c|c|c|}
\hline \multicolumn{4}{|l|}{ Name } & \multicolumn{3}{|c|}{ Patient number: } & \\
\hline \multicolumn{2}{|l|}{ Age: } & \multicolumn{2}{|c|}{ Occupation: } & \multicolumn{2}{|c|}{ Address: } & \multirow[b]{3}{*}{$\begin{array}{l}\text { No. of } \\
\text { WSLs } \\
\left(6^{\text {th }}\right. \\
\text { visit }) \\
\end{array}$} & \\
\hline \multicolumn{4}{|c|}{ Tel. No. 1- } & \multicolumn{2}{|c|}{$2-$} & & \\
\hline Teeth & $\begin{array}{l}\text { No. of } \\
\text { WSLs } \\
\left(1^{\text {st }} \text { visit }\right)\end{array}$ & $\begin{array}{l}\text { No. of } \\
\text { WSLs } \\
\left(2^{\text {nd }} \text { visit }\right)\end{array}$ & $\begin{array}{l}\text { No .of } \\
\text { WSLs } \\
\left.\text { ( } 3^{\text {rd }} \text { visit }\right)\end{array}$ & $\begin{array}{l}\text { No. of } \\
\text { WSLs } \\
\left.\text { ( } 4^{\text {th }} \text { visit }\right)\end{array}$ & $\begin{array}{l}\text { No. of } \\
\text { WSLs } \\
\left(5^{\text {th }} \text { visit }\right)\end{array}$ & & $\begin{array}{l}\text { No. of } \\
\text { WSLs } \\
\left(7^{\text {th }} \text { visit }\right. \\
)\end{array}$ \\
\hline \multicolumn{8}{|l|}{$11=$} \\
\hline \multicolumn{8}{|l|}{$12=$} \\
\hline \multicolumn{8}{|l|}{$13=$} \\
\hline \multicolumn{8}{|l|}{$14=$} \\
\hline \multicolumn{8}{|l|}{$15=$} \\
\hline \multicolumn{8}{|l|}{$21=$} \\
\hline \multicolumn{8}{|l|}{$22=$} \\
\hline \multicolumn{8}{|l|}{$23=$} \\
\hline \multicolumn{8}{|l|}{$24=$} \\
\hline \multicolumn{8}{|l|}{$25=$} \\
\hline \multicolumn{8}{|l|}{$31=$} \\
\hline \multicolumn{8}{|l|}{$32=$} \\
\hline \multicolumn{8}{|l|}{$33=$} \\
\hline \multicolumn{8}{|l|}{$34=$} \\
\hline \multicolumn{8}{|l|}{$35=$} \\
\hline \multicolumn{8}{|l|}{$41=$} \\
\hline \multicolumn{8}{|l|}{$42=$} \\
\hline \multicolumn{8}{|l|}{$43=$} \\
\hline \multicolumn{8}{|l|}{$44=$} \\
\hline $45=$ & & & & & & & \\
\hline
\end{tabular}




\section{RESULTS}

The sample studies were 20 subjects from 1 month to 6 months of orthodontic treatment duration. The prevalence of WSL according to age, gender, and duration of the orthodontic treatment. The mean age of male were $19.43(\mathrm{~S} . \mathrm{D}=6.37)$ and the mean age of female were $19.00 \quad(S . D=7.37)$. The difference was considered as statistically non- significant (P-value >0.05). As shown in Table (1).

Table (1): Relationship between gender and age of patients.

\begin{tabular}{ccccccc}
\hline Variable & Gender & $\mathrm{N}$ & Mean & Std. Deviation & P-Value & T-test \\
\hline Age & Male & 7 & 19.43 & 6.37 & 0.89 & Non \\
& Female & 13 & 19.00 & 7.37 & & Significant \\
\hline
\end{tabular}

Prevalence of WSL among quadrants:

\section{First and second visit:}

In each appointment teeth affected by white spot lesion are shown in Table (2), within the first visit the mostly affected teeth are upper right canine, upper left canine, and upper left lateral incisor, In second visit, the severity of affected teeth changes among the teeth, the most affected teeth are upper left canine, upper left lateral incisor, and lower right canine.

Table (2): WSL at first and second visits of patients.

\begin{tabular}{ccccc}
\hline Teeth/first visit & No. & Teeth/quadrant & $\%$ & Most affected Teeth \\
\hline First quadrant & 9 & 100 & 9 & Most affected teeth are upper \\
Second quadrant & 9 & 100 & 9 & right canine, upper left canine, \\
Third quadrant & 8 & 100 & 8 & and upper left lateral incisor. \\
Fourth quadrant & 3 & 100 & 3 & \\
Total & 29 & 400 & 7.25 & \\
Teeth/Second visit & No. & Teeth/quadrant & $\%$ & Most affected Teeth \\
First quadrant & 11 & 100 & 11 & Most affected teeth are upper \\
Second quadrant & 16 & 100 & 16 & left canine, upper left lateral \\
Third quadrant & 14 & 100 & 14 & incisor,and lower right canine. \\
Fourth quadrant & 14 & 100 & 14 & \\
Total & 55 & 400 & 13.8 & \\
\end{tabular}

No.: Number of white spot lesions ; Teeth/quadrant $=$ total 400 teeth $/ 100$ in each quadrant. Third and fourth visit. 
In the third visit the mostly affected teeth are upper left canine, upper left lateral incisor, and lower right canine, In the fourth visit the most affected teeth are upper left canine and upper left lateral incisor.

Table (3): WSL on third and fourth visits of participants.

\begin{tabular}{ccccc}
\hline Teeth/Third visit & No. & Teeth/quadrant & $\%$ & Most affected Teeth \\
\hline First quadrant & 18 & 100 & 18 & Mostely affected teeth are \\
Second quadrant & 21 & 100 & 21 & upper left canine, upper left \\
Third quadrant & 15 & 100 & 15 & lateral incisor,and lower right \\
& & & & \\
Fourth quadrant & 11 & 100 & 11 & \\
Total & 65 & 400 & 16.25 & \\
Teeth/Fourth visit & No. & Teeth/quadrant & $\%$ & Most affected Teeth \\
First quadrant & 21 & 100 & 21 & The most affected teeth are \\
Second quadrant & 27 & 100 & 27 & upper left canine and upper \\
Third quadrant & 18 & 100 & 18 & left lateral incisor. \\
Fourth quadrant & 11 & 100 & 11 & \\
Total & 77 & 400 & 19.3 & \\
\hline
\end{tabular}

No.: Number of white spot lesions ; Teeth/quadrant = total 400 teeth /100 in each quadrant.

Fifth and sixth visit

In the fifth visit the most affected teeth are upper left canine, and upper left lateral incisor, in the sixth visit the most affected teeth are upper left canine, upper left lateral incisor, and upper right canine.

Table (4): Development of WSL on fifth and sixth visits.

\begin{tabular}{|c|c|c|c|c|}
\hline Teeth/fifth visit & No. & Teeth/quadrant & $\%$ & Most affected Teeth \\
\hline First quadrant & 27 & 100 & 27 & \multirow{5}{*}{$\begin{array}{c}\text { The mostely affected teeth are } \\
\text { upper left canine and upper } \\
\text { left lateral incisor. }\end{array}$} \\
\hline Second quadrant & 28 & 100 & 28 & \\
\hline Third quadrant & 18 & 100 & 18 & \\
\hline Fourth quadrant & 11 & 100 & 11 & \\
\hline Total & 84 & 400 & 21.0 & \\
\hline Teeth/sixth visit & No. & Teeth/quadrant & $\%$ & Most affected Teeth \\
\hline First quadrant & 28 & 100 & 28 & \multirow{5}{*}{$\begin{array}{c}\text { Mostely affected teeth are } \\
\text { upper left canine,upper left } \\
\text { lateral incisor,and upper right } \\
\text { canine. }\end{array}$} \\
\hline Second quadrant & 28 & 100 & 28 & \\
\hline Third quadrant & 18 & 100 & 18 & \\
\hline Fourth quadrant & 11 & 100 & 11 & \\
\hline Total & 85 & 400 & 21.3 & \\
\hline
\end{tabular}

No.: Number of white spot lesions ; Teeth/quadrant = total 400 teeth /100 in each quadrant. 
The prevalence of WSLs on different visit of orthodontic patient is shown in Figure

(1). The frequency of WSLs increased with each visit of orthodontic treatment, the greatest prevalence of WSLs was found in the sixth visit (21.25\%) followed by the fifth visit $(21 \%)$, fourth visit $(19.25 \%)$, third visit $(16.25 \%)$, second visit (13.75\%), and finally first visit $(7.25 \%)$. The mean of all visit equal to $16.45 \%$.

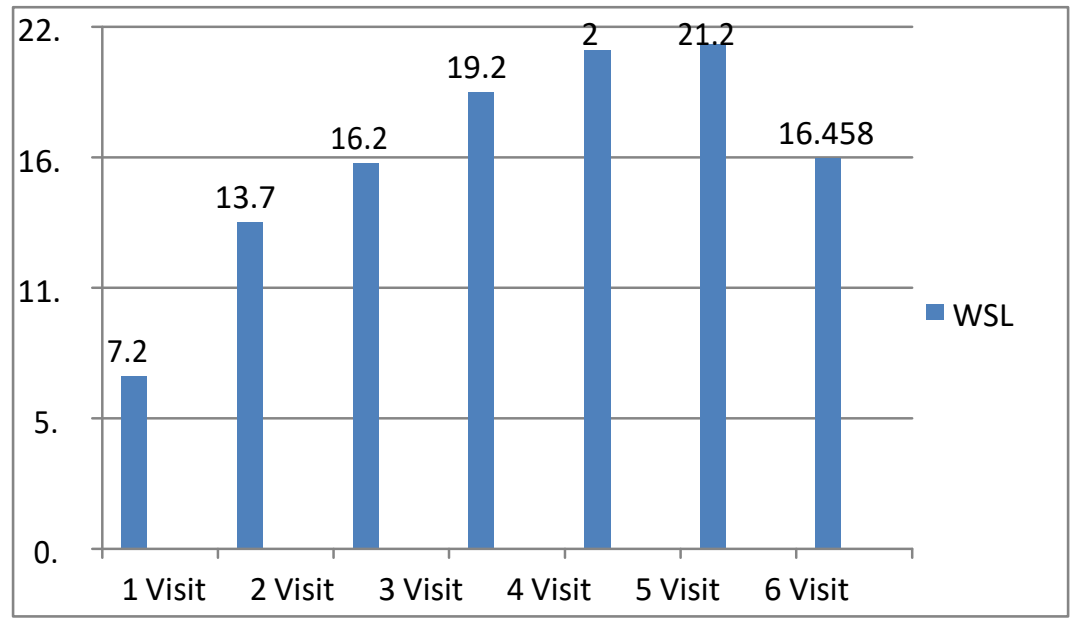

Figure(1): :Representing the occurrence of WSLs on different visits among orthodontic patients

\section{DISCUSSION}

In this study, $7.25 \%$ of teeth had a visual WSL during first months of fixed appliance treatment this rate accreted to $21.25 \%$ for the sixth month of fixed appliance treatment . period of fixed appliance at 6 month The are higher predominance of WSLs suggests that demineralization can quickly become a concern in the presence of fixed appliances when oral hygiene is poor. According to (Ogaard et al,1988),milky appearance become noted after one month of bracket placement but the cavitation may be occur after 6 month ; we have similar results ,with $36 \%$ of patients having visible WSLs , which increased to $46 \%$ in the 12 months of management (Champan et al, 2010). Therefore, it is important for orthodontists to avow poor oral hygiene soon, so that preventive measures can be established before WSLs become growth. Developing WSLs during fixed appliance treatment can be dispute for the dentist. The clinical crown should be clean without calculus, plaque and debris, and the presence of gingivitis can make imaging of WSLs not 
easy. Moreover, to detect incipient WSLs, the tooth must be not covered with saliva ( dried). If not performed these steps, a WSL could easily be hidden. Hence, inspection of these steps should be performed with each appointment for fixed appliance treatment , and each patient should receive a purposedesigned improvement oral hygiene regimen to half the advancement of any cavitation.WSLs affected by many factors like:

\section{Gender}

Female patient with WSLs during fixed appliance become higher (65\%) than male $(35 \%)$ however statistically nonsignificant $\mathrm{P}$-value $<0.05$. The result in line with (Akin et al, 2013) showed that development WSLs have not related to gender. Contrarily, was described by (Gorelick et al, 1982) they discovered the outcome to be $54 \%$ for girls while $44 \%$ for boys. This may refer to obedience and encouragement rather than real gender- based difference.

Age: The result of this cross sectional study showed that there were statistically no significant difference among age of patients in WSLs progress . Similarly with (Sagarika et al, 2012) stated that the age of patient was not a significant factor in the occurrence of WSLs. Contrarily; with (Akin et al, 2013) oral hygiene and age of patient were significant factors in growth WSLs.
Duration of treatment: This survey finds that appreciable hypocacification occurred at six months after bracket placement. Same result, finding by (Julien et al, 2013). According to (Richter et al, 2011) indicated that duration of treatment collinear(onedimensional linear), with increase white spot lesion, means as treatment increase WSLs increase also but (Akin et al, 2013) announced time of duration treatment have not crucial factor in WSLs progress . (Gorelick et al, 1982) were unable to establish the length of treatment time with progress WSLs.

Teeth involved: In this study there was a high occurrence of WSLs appeared on maxillary left canines and maxillary left lateral incisors.Our results are in line with (Khalaf et al, 2014) who showed that the upper canines were the most affected teeth and then lateral incisors. (Julien et al, 2013) also indicated that in the upper arch WSLs 2.5 times more than the lower arch that they occurred most often on the maxillary laterals, maxillary canines and mandibular canines.

\section{CONCLUSION.}

1. $21.25 \%$ of patients in developing WSLs during orthodontic treatments.

2. The upper arch more developed WSLs than the lower arch; they occurred most frequently on the upper 
left canine and upper left lateral incisor.

3. Statistically Gender has no any role in the development WSLs however, clinically significant, female, $65 \%$ and male $35 \%$ (p-value<0.05).

4. Duration of fixed appliance treatment also showed significant increase in the occurrence of WSL.

\section{REFERNCES}

1- Summitt JB, Robbins JW, Schwartz RS. Fundamental of Operative Dentistry: A Contemporary Approach. 3rd ed, Hanover Park, IL. Q uintessnce Pub.2006:2-4.

2- Moghaddam SA, Darekar A, Basade S. White spot lesion in orthodontic. Seminars in Orthod 2013 ; 5(4):35-36.

3- Joshua A, Chapman W, Eugene R, Eckert GJ, Kula KS, Gonzalez-Cabezas C. Risk factors for incidence and severity of white spot lesions during treatment with fixed orthodontic appliances. Am J Orthod Dentofacial Orthop. 2010;138:188-194.

4- Ogaard B. Prevalence of white spot lesions in 19-years-old : a study on untreated and orthodontically treated persons 5 years after treatment. Am J Orthod Dentofacial Orthop.1989 Nov;96 (5) : 423-427.
5- Chapman JA, Roberts WE, Eckert GJ, Kula KS, Gonzalez-Cabezas. Risk factors for incidence and severity of white spot lesions during treatment with fixed orthodontic appliances. Am J Orthod Dentofacial Orthop. 2010;138 (2):188-194.

6- Akin M, Tazcan M, Ileri Z,Basciftci FA . Incidence of white spot lesion during fixed orthodontic treatment. Turkish J Orthod. 2013; 26:98-102.

7- Gorelick L, Geiger AM, Gwinnett AJ. Incidence of white spot formation after bonding and banding. Am J Orthod. 1982 Feb;81 (2)93-98.

8- Sagarika N, Suchindran S, Loganathan S, Gopikrishna V. Prevalence of white spot lesion in a section of Indian population undergoing fixed orthodontic treatment: An in vivo assessment using the visual International Caries Detection and Assessment System II criteria. J Conserv Dent. 2012;15:104-108.

9- Julien KC, Buschang PH, Campbell PM. Prevalence of white spot lesion formation during orthodontic treatment. Angle Orthod. 2013 Jan;83:641-647.

10- Khalaf K. Factors Affecting the Formation, Severity and Location of white spot lesions during Orthodontic Treatment with Fixed Appliances. J Oral Maxillofac Res. 2014; 5 (1) :e4. 
